\title{
LA RECEPCIÓN DEL PSICOANÁLISIS EN EL PENSAMIENTO POSTESTRUCTURALISTA DE LYOTARD: LA CUESTIÓN DEL DESEO Y DEL INCONSCIENTE
}

\author{
Belén Castellanos Rodríguez \\ IES Práxedes Mateo Sagasti, Logroño
}

\begin{abstract}
Resumen.- El siguiente artículo trata de dilucidar las concepciones lyotardianas de inconsciente y de deseo, entendiéndolas dentro de la tradición postestructuralista. Las posiciones postestructuralistas en torno a las citadas cuestiones se hayan en dependencia de un acontecimiento filosófico que es la recepción de la obra psicoanalítica freudiana y lacaniana por parte de dicho movimiento intelectual francés. Por ello, expondremos algunas pinceladas acerca de la reinvención de Freud por parte de Lacan, pensador con el que ajusta cuentas el postestructuralismo; después examinaremos los rasgos que definen la recepción postestructuralista del psicoanálisis; $y$, finalmente, abordaremos el tratamiento concreto de Lyotard en dos de sus obras referidas al psicoanálisis.
\end{abstract}

Palabras clave.- Lyotard, postestructuralismo, psicoanálisis, inconsciente, deseo, Lacan

\begin{abstract}
The following article tries to elucidate the Lyotardian conceptions of the unconscious and desire, understood within the poststructuralist tradition. Poststructuralist positions around the abovementioned issues depend on a philosophical event that is the reception of the Freudian and Lacanian psychoanalytic work by the French intellectual movement. Therefore, we express some hints about the reinvention of Freud by Lacan, a thinker whith whom poststructuralism settles scores, afterwards we examine the characteristics that define the poststructuralist reception of psychoanalysis and, finally, we will address the specific treatment of Lyotard on the basis of two of his works referred to psychoanalysis.
\end{abstract}

Keywords.- Lyotard, poststructuralism, psychoanalysis, unconscious, desire, Lacan

\section{El inconsciente y el deseo en el estructuralismo lacaniano}

Comenzamos este artículo explicando algunas cuestiones sobre el psicoanálisis estructural de Lacan, por parecernos que este pensador hace de eslabón entre el psicoanálisis clásico y el pensamiento postestructuralista, puesto que los filósofos situados en esta órbita ajustan cuentas con un Freud reinventado por Lacan, con un Freud traído al escenario de la Francia de los sesenta.

En muchas ocasiones se habla incluso de una reinvención del psicoanálisis por parte del pensamiento lacaniano, una reinvención que va a descolocar esta disciplina del centraje cientificista al que Freud parecía condenarla, y que va a ligarla a la filosofía, al movimiento estructuralista y al problema del lenguaje. La figura de Lacan supone la inmersión, de Ileno, del psicoanálisis en el campo de la filosofía y la concepción del psicoanálisis freudiano como sistema filosófico que indaga problemas ontológicos, epistemológicos, antropológicos, éticos, políticos, estéticos... 
Además, esta introducción en el pensamiento lacaniano se nos antoja como un paso inevitable para comprender las condiciones de recepción en las que el postestructuralismo se hace cargo de la importancia del psicoanálisis e, incluso, para comprender el psicoanálisis como condición de posibilidad del pensamiento postestructuralista. Constatamos con claridad la profunda intimidad que los liga, hasta tal punto que, a nuestro modo de ver, cada vez que en la obra de Derrida, Foucault, Lyotard o Deleuze, aparece una transformación, por mínima que esta sea, en la lectura de Freud, Lacan, Melanie Klein, etc., reelaboran o revisan toda su obra propia. Así, entendemos que el psicoanálisis tomado de uno u otro modo, aquí o allá, es uno de los pilares del pensamiento postestructuralista, que en absoluto es indiferente a esta disciplina, en la que, según todos ellos, "ya estamos": ya la habitamos querámoslo o no. Podemos decir que el movimiento postestructuralista francés lleva a cabo, como no se había hecho nunca antes, una "crítica de la razón psicoanalítica" y un debate en torno a las síntesis del Inconsciente. No es fácil contestar a preguntas demasiado simples como la que se debate entre un postestructuralismo heredero del psicoanálisis y un postestructuralismo que lo repudia.

Lacan propone un retorno a Freud considerándolo dentro del panorama filosófico. No obstante, esa vuelta a Freud constituirá un nuevo movimiento de delimitación de zonas y obscurecimiento de otras (por ejemplo, se difumina la demarcación, que en Freud habría sido clara, entre procesos primarios y procesos secundarios ${ }^{1}$ ). Lacan pone el acento investigador en el problema del lenguaje, sosteniendo la necesidad o conveniencia de eliminar el referente de todo signo o discurso hasta el punto en el que el lenguaje solo remite a sí mismo. Podríamos decir que la estructura que propone Lacan es algo heterodoxa ya que el operador principal, el centro estructural, que es ocupado por el Falo, es más bien un centro desocupado que consiste en una ausencia. Esto es lo que servirá a Deleuze, en Lógica del sentido, para teorizar el tema de las series móviles gracias a una casilla vacía y también para reformular el sistema platónico en términos de Idea retirada a las alturas. Esto otorga al pensamiento lacaniano especificidades cognoscitivas: el campo de los efectos muestra sus determinaciones causales-estructurales y, al mismo tiempo, las oculta y deforma. Así retomará los conceptos teóricos platónicos de esencia y apariencia. La estructura es una configuración compuesta por un número pequeño y finito de lugares que poseen una función definida formalmente en la relación que cada uno tiene con los otros. Se trata de algo semejante a la symploké platónica de las Ideas, solo que sería una symploké móvil. Las estructuras se constituirían y se transformarían de acuerdo con sus posibilidades, componiéndose los lugares y funciones de diversas maneras $^{2}$. La estructura sería una función-operador en la que caben distintas operaciones que conllevan distintos efectos y que no necesariamente se hacen conscientes ni se someten a los agentes afectados: “...conjunto no (...) totalidad (...) La noción de totalidad sólo interviene si estamos ante una relación cerrada con un correspondiente, cuya estructura es solidaria..."3. Lacan llegará a hacer equiparable la estructura y el significante: "La noción de estructura es ya en sí misma una manifestación del significado (...), la noción de estructura y de significante se presentan como inseparables (...) cuando analizamos una estructura, se trata siempre, al menos idealmente, del significante (...) Nos situamos en un campo distinto al de las ciencias naturales (en las que nadie se sirve del significante para significar (...) Establecer una ley natural es despejar una fórmula insignificante. Mientras menos signifique más contentos nos ponemos (...) Son un puro

\footnotetext{
${ }^{1}$ Sobre la clara distinción entre procesos primarios y secundarios en Freud ver F. Guattari: L'inconscient machinique. Paris, Recherches, 1979. p. 174 en nota a pie.

2 J. Lacan: Seminario 3, Las Psicosis. Ed. Paidós. Buenos Aires, 2010. Clase XIV. p. 261: “ La estructura es primero un grupo de elementos que forman un conjunto co-variante".

3 Ibid. p. 262.
} 
significante (...) y gracias a él tendremos el mundo en nuestras manos"4. Su teoría del significante insiste en que el individuo natural prelingüístico tiene que incorporarse a los sistemas simbólicos, a la cultura y, a su través, a la vida social en conjunto. Estos sistemas simbólicos preexisten al sujeto pero también al juego social, que no se constituirá sino en la inmersión cultural-simbólica. Estos sistemas consisten básicamente en el lenguaje. Saussure había definido el signo, unidad mímima del lenguaje, como la relación entre un significante y un significado, siendo el sujeto hablante el lugar de la significación y del sentido. Para Lacan, el discurso está entre la lengua y el habla, tomando de la primera su soporte material (letra), definido por su localización en el propio discurso y por la diferencia existente entre la inscripción de cada letra. Lacan colocará el significado sobre el significante en lugar de hacerlo al revés, mostrando la resistencia propia del significante a la significación y, así, a la representación. La propuesta lacaniana pretende desvincular al significante de la representación, ya que el significante consiste en su diferencia con otros significantes. La cadena de significantes constituye, en cada una de sus operaciones, un sujeto, y cada significante representa el sujeto para otro significante en un proceso de deslizamiento: "Lo subjetivo aparece en lo real en tanto supone que tenemos enfrente un sujeto capaz de valerse del significante (...) y capaz de usarlo del mismo modo que nosotros lo usamos: no para significar algo sino precisamente para engañar acerca de lo que ha de ser significado (...) Hay uso estricto del significante a partir del momento en que, a nivel del receptor, lo que importa no es el efecto del contenido del mensaje, no es el desencadenamiento en el órgano de determinada reacción debida a la llegada de la hormona, sino lo siguiente: que en el punto de llegada del mensaje, se toma constancia del mensaje. ¿Implica esto una subjetividad? (...) No es seguro (...) Esto es lo fundamental. Salvo mi responsabilidad. La distinción del significante está ahí. Tomo constancia del signo como tal. El acuse de recibo es lo esencial... "5. El sujeto implicado en tal deslizamiento es el sujeto de enunciación: el yo pero un yo que oculta el proceso de su constitución y su significancia así como su propia estructura, que tiene que ser interpretada, descifrada a través de los efectos de sentido resultantes de las libres asociaciones, lo cual implica enunciar la posición del sujeto en la cadena significante. Aquí emerge la verdad lacaniana. Esta verdad no es sino el efecto de la estructuración en la que el sujeto se posiciona respecto al código, respecto a la Ley, que asegura la diferencia, la separación y la sustitución de unos significantes por otros, el efecto de cómo el sujeto habita el lenguaje y se coloca en una relación de poder. Ahora bien, la movilización de la cadena significante y la del sujeto que ella constituye, se dirige a la búsqueda de un significante primordial y final, que haga de límite. Este significante lo hace corresponder Lacan con el Falo, cuya búsqueda coincide con el deseo. Este deseo corresponderá a lo que Heidegger denominaba "aspiración al Ser", pero en Heidegger, tal aspiración no se presenta al modo de un estado psicológico, ni tampoco el Ser sería pensado como un significante sino como condición de posibilidad del lenguaje, que no puede ser tenida (demostrada) sino solo señalada. Además, en Heidegger, ese Ser al que se aspira no es, en absoluto, el signo del Poder social. Como en Spinoza, cada uno aspira mejor al Ser si los demás también lo hacen, es decir, la aspiración al Ser es comunitaria y en un mismo sentido. En Lacan en cambio, la aspiración al Falo es una lucha competitiva por el Poder en la que cada uno pierde en cuanto que otro gana. Encontramos, en Lacan, una reformulación de la Idea platónica como Falo, objeto del amor, del amor al saber impulsado por la carencia que el sujeto siente en el seno de su propio saber. Sin embargo, la erótica platónica, al menos como la entiende Heidegger, también se impulsa a partir de una búsqueda común del pensar. Mientras que en Heidegger se concibe la

\footnotetext{
${ }^{4}$ Ibid. p. 262-263.

5 Ibid. p. 266.
} 
Idea de Bien de modo fundamentalmente ontológico, en Lacan parece tener carácter gnoseológico e incluso moral, haciendo sentir una falta en el saber o incluso una falta de poder. Parece que el sujeto tiende a tener el Falo al igual que el amante platónico tiende a alcanzar la Idea de Bien. Desde Heidegger, podemos aspirar a ella sin cesar para tomarla como horizonte desde el cual conocer, sin ser ella misma conocida. Sin embargo, Heidegger no hunde este saber del límite en una cuestión de poder social o políticoactual.

El sistema significante es, en Lacan, el Inconsciente, del cual dice que está estructurado como un lenguaje. El Inconsciente sería la parte supraindividual del discurso que falta a la disposición del sujeto yóico, y que lo invade y lo sorprende con formaciones a las que no puede atribuir sentido. Lacan denomina fantasmas a las escenas en la que el deseo inconsciente se presentaría como realizando o alcanzando al Falo. No sabemos cómo entender tal cosa, a no ser que asimilemos el hecho de alcanzar el Falo al hecho de hacerse con el poder o de ser satisfecho por el otro en las propias demandas vehiculizadas a través del lenguaje y de sus lagunas ${ }^{6}$. Nosotros vemos en esta aspiración al Falo un aire de conquista y de rivalidad que nada tiene que ver con el deseo del Ser ontológico propio de los griegos y de Heidegger, que en ningún momento están hablando de un deseo destinado al consumo.

El sujeto psicoanalítico es un sujeto escindido en dos cadenas significantes, una consciente y otra inconsciente (discurso del Otro), separadas por la operación que da lugar al sujeto, es decir, por la represión primaria, por la que la cadena significante sufre la caída de significantes al campo del inconsciente. El proceso psicoanalítico trataría de reconstruirlo. La denominada por Freud "fantasía inconsciente" consiste en intentar representar las irrepresentables estructuras fundantes del sujeto. Tenemos un Lacan que inicia así una crítica a la teoría moderna de la representación, que consistiría en afirmar que cada dominio (pensamiento, lenguaje, arte...) no funciona con elementos que sean presencias delegadas de otros territorios, sino que operan con elementos propios, siendo lo Real también un registro, pero un registro inaccesible a la experiencia subjetiva, irrepresentable, semejante al noúmeno kantiano o a la Substancia spinozista. No obstante, el psicoanálisis parece pretender orientarse o incitar a lo Real. Lacan va a romper con las correspondencias significado-significante para presentar una periodicidad variable del significado: la secuencia de significantes reformula retroactivamente al significado, con lo que el emisor solo entiende lo que ha dicho después de decirlo.

El Edipo, entendido como Complejo, es para Lacan un mito, así que reformula la teoría de Edipo como estructura, convirtiéndose las figuras parentales en operaciones del sujeto que asimismo lo constituyen como tal. Son códigos en los que el sujeto se incorpora: "El complejo de Edipo (...) Su grado de elaboración sólo es tan esencial para la normalización sexual porque introduce el funcionamiento del significante en tanto tal en la conquista del susodicho hombre o mujer (...) Es necesario que el sujeto adquiera el orden del significante, lo conquiste, sea colocado respecto a él en una relación de implicación que lo afecta en su ser, lo cual culmina en la formación de lo que llamamos en nuestro lenguaje el superyo (...) El superyo plantea la cuestión de saber cuál es el orden de entrada, de introducción, de instancia presente del significante que es indispensable para que un organismo humano funcione, organismo que no sólo debe vérselas con un medio natural, sino también con un universo significante" 7 . No obstante, este Edipo estructural conserva la caracterización de universalidad que Freud le atribuye. De tal forma ocurre que el sujeto

\footnotetext{
${ }^{6}$ Cfr. Para seguir esta cuestión en términos lacanianos ver J. Alemán y S. Larriera: Lacan: Heidegger. El psicoanálisis en la tarea del pensar. Ed. Miguel Gómez. Málaga, 1998. pp. 262-266.

7 J. Lacan: Seminario 3, Las Psicosis, Clase XIV. op.cit. pp. 269-271.
} 
queda prendido al deseo del Otro, ya que si se desvinculara perdería su identidad, la subjetividad autónoma que requiere la asunción de una falta, y si no se desvinculara, no adquiriría independencia ninguna. Por eso dirá Lacan que la producción de un sujeto implica la alienación en los significantes del Otro. Lacan afirma que "el deseo es el deseo del Otro". Podemos interpretar aquí cuatro cosas: se desea al otro, se desea lo mismo que desea el otro, se desea ser deseado por el otro y se desea desde el inconsciente. Las tres primeras modalidades apuntan al Falo, significante de una completud inicial 0 supuestamente inicial. Parece que se habla de un todo imposible pero de un todo al que, no obstante, se aspira. De ahí la afirmación lacaniana de que lo Real es imposible, es imposible para el sujeto, es irrepresentable. La cuarta modalidad nos lleva a otra cuestión, cuyo carácter seguimos en nuestra investigación: el deseo es maquinado desde el Inconsciente.

Lacan entiende que la lengua es una estructura, un conjunto de signos incompleto que conecta el sentido con el goce y que estructura el cuerpo humano (un cuerpo que sería naturalmente sexuado), apartándolo de la armonía natural e inscribiendo en él una herida que resulta esencial en la comprensión de la existencia humana: "El cuerpo mismo es originalmente este lugar del Otro, puesto que ahí desde el origen se inscribe la marca en tanto significante" ${ }^{8}$. Solo como resto, como consecuencia colateral de esta operación, surgiría el inconsciente. Esto está muy alejado del Inconsciente propuesto por el postestructuralismo, así como del Inconsciente al que alaba Nietzsche. El postestructuralismo está tratando con un Inconsciente constituyente, no constituido. De este modo, dada la desemejante forma de valorar la génesis y la naturaleza del Inconsciente, encontramos, en consecuencia, también un modo totalmente diferente de entender el deseo (o en palabras de Lacan, el goce) como actividad propia del Inconsciente. Lo que aquí también está en juego es la concepción del fantasma. En Lacan, el deseo del inconsciente es fantasmático y así, el acceso a lo Real está filtrado por el fantasma, que es la obra que el significante ha realizado en lo Real. De este modo, el inconsciente sería una instancia estéril que no maquina sino que invoca una escena en la que queda atrapado todo deseo, circulando por unos cauces prefijados que nunca es capaz de desbordar. Se está negando la capacidad del deseo para reinventarse, es decir, para retrotraerse a su punto cero y comenzar de nuevo el camino. Con el pensamiento postestructuralista, hablamos de un Inconsciente Ontológico que viene a equivaler al Pensar del Ser al que, con otros filósofos, denominamos logos o nous. El Inconsciente, entonces, se constituye como el límite posibilitante que liga la pluralidad óntica.

Lacan, como los pensadores postestructuralistas, estructura los fundamentos para una crítica a la lógica consumista del Capital, pero mientras el primero se lamenta por la pérdida del respeto que impone la expansión de la técnica al desarticular la castración ${ }^{9}$, permitiendo la reunión entre el sujeto y el goce del objeto; el postestructuralismo sacará al deseo de la lógica de la carencia, del anhelo y de la mistificación, para llevarlo al ámbito en el que la dualidad sujeto-objeto se rompe, y hace que el deseo deje de ser consumidor para ser productor, evaluando, desde ahí, más positivamente, la técnica. El postestructuralismo abandona ese deseo significante, dependiente de la Ley del Falo y atravesado siempre por el discurso. Notemos que en Lacan, la castración impone una falta que constituirá la condición de posibilidad del deseo, y recordemos, para acabar de entenderlo, que el modo de aceptar la castración es la sumisión a la Ley y que el plusgoce, por tanto, es un goce fálico, un goce superyóico, y tal goce se presenta como acontecimiento artificial (al igual que el amor), como suplencia de lo imposible, del goce

8 J. Lacan: Seminario 14:Lógica del fantasma. Clase 20. Del 31 de Mayo de 1967. http://www.tuanalista.com/Jacques-Lacan/14956/Seminario-14-La-logica-del-fantasma-pag.1.htm

${ }^{9}$ S. Larriera y J. Alemán: Lacan: Heidegger. El psicoanálisis en la tarea del pensar. op.cit. p. 28. 
sexual. En definitiva, el mpostestructuralismo se descuelga de esa herencia hiperplatónica en la que el deseo se halla en dependencia del esclarecimiento del problema de la participación. El deseo ya no es de lo que falta ni de lo que hay, ya no aspira a ningún modelo, ni siquiera a un objeto estructural, sino que despieza los modos presentes y virtualiza inventando simulacros. El deseo es maquinación del Inconsciente, y éste es punto de partida y no de llegada.

El goce lacaniano es un goce del super-yo. Es un goce que se retuerce en los confines de la prohibición. El goce lacaniano es un goce que se siente en el camino de vuelta de la represión, es el goce que brinca en las relaciones de dominación. El goce lacaniano es un goce no solamente ligado sino estructurado por el fantasma que somete las pulsiones al imaginario, que dirige el deseo hacia la prohibición del deseo mismo. En el postestructuralismo, en cambio, el deseo en sentido ontológico es previo a toda ligadura y previo a la instauración del discurso cultural. Es la maquinación del Inconsciente, fuente inmanente de todas las posibilidades de la cultura.

\section{Características de la recepción del psicoanálisis por parte de los pensadores postestructuralistas en general.}

- Una trayectoria en la que podemos leer una importante ambivalencia hacia el psicoanálisis y hacia la obra de Freud en particular y un diálogo constante con su contemporáneo Lacan. Cuando decimos ambivalencia no queremos decir falta de rigor al enfrentarse al tema ni vaivén arbitrario de posiciones respecto del mismo. De hecho, creemos poder definir esta ambivalencia a partir del establecimiento de dos etapas. Una primera podría describirse como filiación a (que no militancia en) el pensamiento freudiano, tal vez bajo el influjo de Lacan, tal vez bajo la idea de un parentesco FreudNietzsche (tomando sobre todo al Nietzsche de La genealogía de la moral). Una segunda etapa, que comienza con la década de los setenta, estaría marcada por un progresivo desapego o escepticismo hacia las "promesas" de la revolución psicoanalítica. En este período, el pensamiento de la Diferencia, que tomaba a Freud como uno de sus precedentes, como alguien que había abierto el paso, se vuelve a menudo contra él, que parece enredado en la puerta de salida de la metafísica tradicional. Esta crítica no es grosera sino que más bien consiste en un interrogar, en un pedir cuentas a un psicoanálisis que, institucionalizado pero también marginado, demanda una interpelación de quienes esperaban algo más de él; a un psicoanálisis que no ha sabido reinterpretarse, reproponerse, y que ha acabado siendo un vehículo más de legitimación del Poder, un discurso de "verdad" y un vigilante delegado. A partir de esta observación, el postestructuralismo releerá a Freud buscando la pista de estas consecuencias. Esta nueva lectura se hará ya desde la sospecha.

- Una crítica al familiarismo en la concepción social del psicoanálisis. Se procede, en muchas ocasiones, apelando a Marx. Entendemos que Marx es un filósofo que ha tenido, sin embargo, una recepción, por parte del postestructuralismo, muy semejante a la de Freud. Quizá convenga señalar aquí que estos dos pensadores, que no forman parte de las filias más exaltadas de los franceses de la Diferencia, pero mucho menos de sus fobias, y que han sido tratados con respeto, incluso con afecto, tienen algo muy importante en común: han experimentado una implantación social relevante, se han constituido Internacionales a su alrededor, dando lugar a efectuaciones tan convulsivas y tan polémicas como lo son los países del socialismo real y los divanes psicoanalíticos. Tal vez a filósofos como Lyotard, Derrida, Foucault, Deleuze y Guattari, "el porvenir de una ilusión" les pareciera más amable que el advenimiento de un presente actual, o tal vez el pensamiento de la Diferencia exige subvertir todo aquello que alcanza las alturas del Poder. Retomando cuestiones menos vagas, diremos que, aunque el postestructuralismo 
usó a Marx para cuestionar el familiarismo de Freud y su olvido de un campo social políticamente anterior, y a Freud para poner en cuestión la creencia de Marx en un sujeto de la emancipación, no significa esto que hayan dado lugar a ningún tipo de freudomarxismo. Muy al contrario, anunciarán el fracaso del mismo y apostarán, no por los elementos que los hacen compatibles, sino por los elementos que los deconstruyen mutuamente. El freudomarxismo aparece, entonces, ya como una especie de repartición salomónico-hegeliana en la que Marx se queda investigando la zona pública y Freud la privada, como si tal paralelismo se pudiera dar, como si uno no estuviera ya constituyendo al otro, como si no hubiera una microfísica del poder. El freudomarxismo más vulgar acabaría encerrando al deseo en casa y a la producción en la fábrica y creando una pareja con la "masculinidad" del marxismo y la "feminidad" del psicoanálisis. Algunos feminismos psicoanalíticos rozarían este planteamiento haciendo de la Ley, la conciencia, la razón y el interés la esencia del hombre; y del símbolo, el inconsciente, la irracionalidad y el deseo, la esencia de la mujer. Si no nos perdiéramos en el mito y los tópicos, este planteamiento podría llevarnos por caminos interesantes, pero subordinado al corsé del malentendido par base-superestructura (reducido por cierto economicismo) nos conducirá a una dialéctica bastante estéril que no tiene en cuenta la "feminización" de la producción a la que estamos asistiendo en la época postfordista. No obstante, hemos de señalar que con la denominación "freudomarxismo", aunque nos puede servir para orientarnos, no estamos hablando de una escuela en sentido estricto, y por tanto, tampoco hemos de presuponer una unidad de discurso en aquellos pensadores que fueron encasillados dentro de este concepto. Lo que si podemos decir es que advertimos en todos los filósofos a que hace referencia una formación marxista y una formación psicoanalítica. Sin embargo, bajo este esquema, podemos encontrar desde intelectuales que eligen lo más débil de cada una de las dos escuelas o de sus representantes más notables, dentro de un debilitamiento militante de ambos movimientos y de una reclusión academicista, hasta aquellos que mantuvieron una militancia activa en ambas disciplinas, no siempre ortodoxa pero sí orientada al campo de la praxis social y del impulso revolucionario. Éstos últimos nos parecen los más interesantes y en ellos podemos descubrir experiencias de renovación pedagógica y social inspirada por el freudomarxismo. Es un prejuicio entender la fertilidad del movimiento freudomarxista a partir de una especie de yuxtaposición o de relleno mutuo, es decir, a partir de la idea de que marxismo y psicoanálisis se completan el uno al otro en sus presuntas lagunas. De este estilo son las afirmaciones según las cuales, el marxismo descuidó el tratamiento de la subjetividad humana, de sus emociones, de sus motivaciones, de sus potenciales intelectuales, de sus posibles patologías, etc. Asimismo, y siguiendo esta intuición, el psicoanálisis habría descuidado el campo político y productivo como campo de creación de relaciones sociales y con ello personales, y por tanto como variable importantísima de influencia y de catexis psicológica, que nos daría cuenta del funcionamiento de numerosas estructuras mentales a nivel tanto individual como colectivo. Aquí queremos hacer notar, con toda seguridad, el prejuicio y desconocimiento teórico que esta percepción supone. Para cualquier lector de Marx, capaz de profundizar un mínimo, es del todo evidente, que hay en Marx no solo apuntadas ciertas ideas colaterales sino todo un sistema encargado de dilucidar el problema de la subjetividad y de los afectos y emociones humanas. Concretamente podemos hacer referencia a numerosas páginas dedicadas al desenmascaramiento de la idea metafísica de un yo unitario y autoidéntico; al desenmascaramiento de una conciencia individual originaria, libre y dueña de sí misma; al desenmascaramiento de la inocencia y humanidad de ciertos afectos a partir del análisis y genealogía de las instituciones encargadas de promoverlas, legitimarlas y reproducirlas, etc. Por no extendernos demasiado, podemos resumir diciendo que hay, en la órbita del marxismo, tres aportaciones teóricas fundamentales para el campo de la psicología, sobre todo para el área de la psicología de investigación pero también para la psicología, si no clínica, sí 
de prevención, a saber: toda la línea temática desarrollada en torno al tratamiento de la alienación; el propio núcleo del materialismo filosófico marxista, según el cual partimos de la observación de que es "la vida la que determina la conciencia" y no al contrario (así nos ponemos en la pista de despegue para revolucionar la psiquiatría desde los cimientos ya que se nos coloca en un nuevo paradigma de observación de la conducta y motivación humana, abriendo todo un panorama de investigación que desplaza considerablemente los horizontes de los estudios sobre la mente); y, por último, el principio implicado en la organización política, que promueve desde bases teóricas, la crítica y la autocrítica, que bien podría estar llamada a sustituir terapias psicológicas al estilo más tradicional, implicándose además en el ámbito de la praxis vital y dándole a la psicología preventiva el contexto adecuado, es decir, el ámbito laboral o de producción económica, así como el de la práctica política (decimos su ámbito adecuado porque tal vez la resolución de problemas sea más eficaz, si tiene lugar allí donde se originan esos problemas y ese lugar es, desde luego, la comunidad económica política y libidinal). Fijémonos ahora en Freud y el psicoanálisis en general. ¿Cómo podríamos decir que el trabajo teórico del mismo no tiene en cuenta lo político-social? Tal vez no encontremos ningún enfoque psicológico que tome tan en consideración como el psicoanálisis lo hace, el carácter económico y construido, social y políticamente, de la denominada conciencia individual. Encontramos solo en Freud (sin añadir a otros pensadores del psicoanálisis) numerosas aportaciones válidas para el pensamiento político. Por citar algunas de ellas, señalaremos las siguientes: su propio núcleo teórico, que no es otro que la teoría de la represión, esquema bajo el cual se explicará de modo distinto al tradicional, el inicio de la civilización, pero también la base para comprender las miles de conductas patológicas que pueblan nuestra cotidianidad; el tema de la transferencia, que tanta luz arroja sobre los entresijos de las relaciones de poder asociadas a asuntos como la sugestión o el lenguaje como arma política de doble filo y como cristalización y útil de reproducción de la ideología imperante; reformulación del pasaje del amo y el esclavo y conexión entre la familia, tal y como la conocemos, y las estructuras de poder macropolítico; crítica de la religión monoteísta y de las supersticiones e idealismos varios dentro de un contexto antropológico que las relaciona de nuevo con los afectos desprendidos e intensificados de ciertas relaciones sociopolíticas que se plasman y se reproducen a partir, sobre todo, de la instauración del sentimiento de culpabilidad y del espíritu de venganza, que nos llevan por los caminos de una repetición constante de la historia acompañada siempre por la promesa de una ilusión; exposición del choque fatal entre la moral imperante y las pulsiones humanas; estructuración explicativa de una economía libidinal y de sus modos burgueses, y un largo etc. Así, la fértil colaboración entre marxismo y psicoanálisis no pasa, entendemos, por una yuxtaposición teórica de ambos en la que uno rellanara supuestas lagunas en el otro, sino por la recuperación del potencial revolucionario de ambas corrientes, más allá de los estrechos límites del academicismo anodino, pasa por la adecuada "vigilancia" que uno puede suponer para el otro en lo que se refiere a la implantación social, debido a la capacidad que el marxismo tiene para prevenir algunos vicios habituales, no ya en la teoría, sino en la práctica del psicoanálisis como pudieran ser el pesimismo político que puede desembocar en la parálisis propia del cientificismo y en la consiguiente medicalización de la sociedad, que nos puede devolver al moralismo (más peligroso que nunca pues disfrazado de salud pública) y a la reacción. A su vez, debemos destacar también la capacidad del psicoanálisis para prevenir muchas de las desviaciones que hacen peligrar una adecuada implantación social del marxismo, como puedan ser el sectarismo, el elitismo como mala comprensión del papel de la vanguardia revolucionaria, el adoctrinamiento moralista como mala comprensión de la formación colectiva y de la reeducación comunista, la reproducción de las relaciones burguesas de poder en el seno de las organizaciones políticas (clasismo, reparto de tareas según la división metafísica del trabajo intelectual-manual, adopción de hábitos familiares patriarcales, sentimientos de 
pertenencia al grupo construidos sobre el narcisismo y la frustración, búsqueda de un líder carismático que cumpla el rol de garante en la recuperación del paraíso edípico perdido, etc).

-Reconocimiento de la fuerza del psicoanálisis en su crítica a la consciencia, al sujeto presente a sí mismo, autónomo, autoidéntico y dueño de su voluntad. Se comprenderá casi siempre que el uso que Freud y Lacan hacen del viejo y metafísico concepto de "sujeto" es porque se presentaba como instrumento que puede ser interesante, siempre y cuando no se le otorgue valor de verdad ni primacía ontológica, ni significación demasiado fija.

-Reclamación del psicoanálisis y de la obra freudiana como formando parte del campo filosófico, entendiendo la resistencia freudiana a ser considerado dentro del mismo como la expresión de un prejuicio cientificista propio de su época, que Lacan habría evadido ya en gran medida. Asimismo, se le obligará a la filosofía a entrar en el psicoanálisis o más bien, se empujará a la filosofía a reconocer que el mundo en el que habita es ya un mundo revolucionado por el psicoanálisis.

-Revisión de la teoría del significante de Lacan, por la que el postestructuralismo siente enorme interés, ya que comparte con ella la idea de la resistencia a la significación, pero encuentran en su seno el peligro del significante primordial, del imperialismo de ciertos significantes, y problematizan la cuestión de la caracterización de ese significante como ausencia que constituye al sujeto; sujeto en el que quedará apresado el deseo, entendido erróneamente como una falta y no como una afirmación o sobreabundancia.

-Denuncia el propósito traductor del psicoanálisis, su voluntad de representar el inconsciente y de hacerlo hablar en el lenguaje metafísico de la presencia. El inconsciente habría sido el más grande descubrimiento de Freud pero habrá que desterritorializarlo de un panorama anclado en el pensamiento metafísico tradicional. El postestructuralismo dice que el Inconsciente es la Diferencia, alteridad radical que no puede ser nunca presente ni mucho menos emerger en la conciencia.

-Denuncia de la concepción del deseo como carencia. Encontraremos en los franceses de la diferencia la reproposición del deseo como algo pre-individual y no nacido de la Ley. Así, entramos con el postestructuralismo, en el escepticismo ante la teoría de la represión. Se reclama el deseo como algo más que el producto de una negación dialéctica, que lo encerraría ya en la trampa del Poder, aniquilando su carácter revolucionario, su carácter de alteridad que pone en cuestión todo gobierno, más allá del "niño desobediente".

-Problematización en torno a la cuestión de la interpretación. Apuestan por la interpretación si se entiende por ella la afirmación de un juego que no se vuelve hacia el origen, que ha renunciado a él e intenta pensar más allá del humanismo y de su sueño onto-teológico, renunciando al fundamento tranquilizador. En cambio, renegarán de una tarea interpretativa direccionada en busca de un origen transcendente al movimiento de la propia interpretación, en busca de una solución para descifrar la verdad. Ninguno de los pensadores del postestructuralismo comparte nada con un trabajo de interpretación vivido como penoso esfuerzo, como moneda de cambio para apropiarse de un discurso de verdad.

-Comunidad con el psicoanálisis respecto a la consideración del sentido como un efecto de superficie, constituido a partir del sinsentido y no en profundidad oculta alguna. 


\section{De la posición psicoanalítica a la concepción de Lyotard}

Para entender la recepción de Freud y el psicoanálisis por parte de Lyotard, vamos a centrarnos principalmente en dos libro suyos, ambos compuestos por una serie de artículos recopilados por el propio pensador: A partir de Marx y Freud, editado en 1973; y Dispositivos pulsionales, de 1981. Estos textos irían perfilando la dirección del pensamiento lyotardiano hacia su propia teoría del deseo que quedaría plasmada un poco más tarde en una de sus obras más paradigmáticas: Economía libidinal. Podríamos señalar como dato que, tal vez, Lyotard comenzara a tener sus contactos más cercanos con el psicoanálisis, a partir de su época en el grupo Socialismo o Barbarie $^{10}$, ya que supone un punto de encuentro con la figura de Cornelius Castoriadis, otro de sus componentes, filósofo y psicoanalista que, aunque finalmente se aleja del pensamiento postmoderno, comparte con éste algunos de sus planteamientos ${ }^{11}$.

Ya que nos disponemos a indagar en Lyotard la recepción de otro pensador, empezaremos comentando el modo en que Lyotard entiende la cuestión de la recepción, y por tanto, la importancia de un texto. Lyotard comprende que: "La importancia de un texto no es su significación sino lo que hace y hace hacer: la metamorfosis de esta energía potencial en otras cosas, otros textos"12. Sin lugar a duda, Freud, su obra, aparece como uno de los textos desde los que Lyotard ha derivado. Al igual que ocurre con otros intelectuales del postestructuralismo francés, podemos observar en Lyotard un expreso interés por Marx y Freud, por la potencia de sus obras. Del mismo modo, tenemos que

${ }^{10}$ Este grupo publicó una revista entre los años 1949 y 1965. Después, el grupo se disolvió pero aún es considerado fuente de inspiración teórica de Mayo del 68.

${ }^{11}$ Cfr. Castoriadis se decide por la modernidad como contexto de ideas en el que mejor se encuadra la lucha por la emancipación. No obstante, advierte problemas inherentes a este modo de pensamiento, de entre los cuales destacaría la utopía de un dominio ilimitado de la razón. De éste se seguirán otros como una visión globalizadora de la Historia como progreso y la idea de una razón uniforme y universal. Castoriadis haciendo, a nuestro modo de ver, una ambigua y equivocada identificación entre lo que es la época postmoderna y el pensamiento o filosofía de la postmodernidad, encuentra que el marcaje es una evaporación del conflicto político devenido conformismo generalizado. Aunque comparte alguna de las críticas a la modernidad, no aceptará las "soluciones" que tildará de "agnosticismo político" estratégicamente evasivo. Los movimientos que surgen en esta época los encuentra miopes, es decir, tan sectoriales, que han sido incapaces de afrontar el problema político global. Encontramos que Castoriadis, tal vez, no sabe ver el potencial de estos movimientos (feminismo, ecologismo...) respecto a las posibilidades filosóficas que ofrecen desde el momento en que desplazan las percepciones y ponen en tela de juicio los pilares fundamentales del actual sistema político. Castoriadis considera que la decadencia comienza con el segundo Heidegger, filósofo del cual nos hemos nutrido aquí, enormemente, para el desarrollo del presente trabajo. Castoriadis considera que éste abre un período caracterizado por el fin de las posibilidades críticas, entendiendo que su enfoque estético hace referencia a "estética" en el sentido más vulgar del término: estética como frivolidad. Castoriadis cree que hay que abandonar la pregunta ontológica que nos lleva a "sendas perdidas" (¿y esto no es conformismo?). El proyecto de Castoriadis, finalmente, tiene muy poco que ver con el camino que aquí queremos seguir. Se trata del proyecto de la autonomía humana, aceptando los descubrimientos de Marx y Freud pero invirtiendo la fórmula "determinista" de que la vida determina la conciencia o de que el Inconsciente determina la conciencia, para decir que la conciencia autónoma y libre puede conquistar los obscuros terrenos del ello. Planteó la imaginación como productora de representaciones y entenderá la práctica psicoanalítica clínica como praxis política. Como vemos, estamos en las antípodas de nuestro análisis. No obstante, resulta interesante cómo recorridos bibliográficos parecidos, pueden llevar a trazar caminos tan dispares. Para más información, podríamos ver algunas de las obras más importantes de C. Castoriadis al respecto: La institución imaginaria de la sociedad, vol. I Ed. Tusquets. Barcelona, 1983, sobre todo pp. 175-185; Los dominios del hombre. Ed. Gedisa. Barcelona, 1988; también sus artículos "El campo de lo social histórico" (http://www.franjamoradapsico.com.ar/home/descargas/resumenes/2\%20a\%C3\%B1o/DHEP\%20I/Castoriadi s,\%20C\%20-\%20El\%20campo\%20de\%20lo\%20social\%20hist\%C3\%B3rico.pdf) y "Contra el postmodernismo: el reino del conformismo generalizado" (http://es.scribd.com/doc/23479562/CastoriadisContra-El-Posmodernismo).

${ }^{12}$ J. F. Lyotard: A partir de Freud y Marx. Ed. Fundamentos. Madrid, 1975. p. 10. 
decir que estamos lejos de encontrarnos ante ningún tipo de freudo-marxismo. Del freudomarxismo es típica la fórmula de la complementariedad, que ahonda en el tan malentendido esquema base-superestructura, bajo el cual Marx nos vuelve a la imagen del topo que rastrea los subsuelos y Freud se ocupa, mientras tanto, de los "efectos espirituales". Nada más ajeno a esto que el dibujo de Lyotard, que rechaza ya tal esquema de composición: "No existe en ninguna parte un orden económico primero, seguido de efectos ideológicos, culturales, jurídicos, religiosos, familiares..."13.

Lyotard, como todo postestructuralista, tiene su particular crítica contra la dialéctica, pero en este caso, si bien advierte a un Freud aún encadenado a algunos de los principios de la misma, también lo entiende como uno de sus principales deconstructores. El primer Freud aparece reflejado en afirmaciones lyotardianas como: "En Freud continúa, también en Spinoza o en Marx, la religión de la necesidad. Es lo que queda por destruir, ya que si es atacada caerá el resorte del capital, la necesidad de la igualdad en valor de términos de cambio" ${ }^{14}$. También podríamos encontrarlo, en la siguiente frase, la cual, aunque dirigida a cierta manera de hacer política, recuerda demasiado al modo de hacer terapia en el diván psicoanalítico de la reviviscencia: "El deshonor de los políticos es la transformación del pasado en verdad del presente"15. Pero lo más destacable es el uso que hace Lyotard de Freud, convirtiéndolo en puntal fundamental para la destrucción del pensamiento dialéctico. Para ello, veámos un par de citas: "Freud supone el rechazo inicial del principio de la unificación de los fenómenos psíquicos por la conciencia y la hipótesis de un principio de dispersión (...) insuprimible (...) que no deja de sostener la labor de desplazamiento (...) que se lleva a cabo. Eso quiere decir que es inútil buscar en el fracaso de determinada fórmula (...) la razón (dialéctica) de la invención de la siguiente. Todas las fórmulas son fracasos y éxitos, no se suceden más que en la historia de superficie, son contemporáneas unas de otras en el subsuelo en que el deseo (...) engendra (...) puntos de vista contrarios"16; "Freud (...) osó escribir que una carga no es nunca abandonada por la libido por otra mejor; que hay más bien carga de tal región del cuerpo (...) y de tal otra; y que las dos, no pensables, son, al menos, posibles; que la una ignora a la otra (...) Es la misma energía, del mismo nivel, depositada al mismo tiempo, en el mismo lugar, pero produciendo productos diferentes (...) Lo que la dialéctica olvida es que hay olvido, y que el olvido es que todo sea conservado"17. De esta forma peculiar, Lyotard reescribe la idea heideggeriana de un Pensar del Ser, un pensamiento sin sujeto en el cual todo es cobijado para otro levante. A este logos nosotros lo hemos denominado, en acuerdo con el pensamiento postestructuralista, Inconsciente.

A lo largo de su obra, Lyotard hace referencia, no pocas veces, a la deuda conceptual que tiene con Freud, reconociendo que el término deseo, asunto en torno al cual gira, en gran parte, su pensamiento, es un término tomado del padre del psicoanálisis. A partir de esta recepción, lo que va a hacer Lyotard es problematizar tal concepto, mostrando las ambigüedades, ambivalencias o imprecisiones con las que Freud presenta habitualmente a uno de los elementos más importantes de su obra. Lejos de buscar contradicciones que tiren por tierra los textos freudianos o que nos pongan en la pista de su superación, esta particular vacilación con la que Freud nos transmite el concepto de deseo o la equivocidad con la que hace uso del mismo, sirve a Lyotard como plataforma a partir de la cual dibujar derivas de pensamiento.

En primer lugar Lyotard distinguiría, "a partir de Freud" dos polos del término deseo. Por

\footnotetext{
13 J. F. Lyotard: Dispositivos pulsionales. Ed. Fundamentos. Madrid, 1981. p. 31.

14 J. F. Lyotard: A partir de Marx y Freud. op.cit. p.21.

15 Ibid. p.37.

16 J. F. Lyotard: Dispositivos pulsionales. op.cit. p.75.

17 J. F. Lyotard: A partir de Marx y Freud. pp.17-18.
} 
un lado, encontramos lo que el intelectual francés denominará deseo-voto ${ }^{18}$, polo éste que encierra una de las concepciones del psicoanálisis más criticadas en el presente trabajo: el deseo entendido desde la carencia, herencia platónica que pervive en el cuerpo teórico del psicoanálisis freudo-lacaniano. Desde esta perspectiva, el deseo supone una negatividad y una dinámica teleológica. Lyotard afirmará que esta consideración del deseo nos obliga a hablar no ya del "puro deseo" sino de una figura del deseo. Este polo deseovoto, nos lleva a la apreciación de que, más que con el deseo, estamos tratando con una figura del deseo, con un dispositivo del deseo y no con su libre fluir. Se trata de una operación de regulación que el proceso secundario hace sobre el deseo. Debemos hablar de dispositivo desde el momento en que el deseo-voto lleva inyectado un sentido y busca una realización, la disposición de un objeto. Se trata de "un deseo" direccional y no del deseo en términos ontológicos. Aquí el deseo sería aquello que se mueve hacia algo, haciéndolo aparecer ${ }^{19}$.

Por otro lado, tenemos el otro polo del deseo, el deseo-libido, entendido como potencia en acto, con un carácter no finalista sino repetitivo y ligado al proceso primario, prelingüístico, previo a la configuración de sentido alguno, de unidad alguna. Estamos hablando aquí de una energía transformable, nunca de un actual. Es deseo desbordante, no regulado sino fluyendo libremente, fuera de dispositivos, constituyendo una amenaza para los mismos, ya que, no siendo un flujo ligado, es desregulador y desorganizador. Nos lleva siempre al punto cero y al punto infinito, que caracterizan a la Substancia en sentido spinozista. Lyotard no deja de encontrar en el propio Freud el germen de esta perspectiva, para lo cual nos remite al tan nombrado por nosotros Más allá del principio del placer, donde ya habíamos atisbado la idea de un deseo ontológico. Ya no estamos en el deseo de algo, sino en el deseo sin más. Ya no estamos en el sentido del deseo sino en el juego positivo, afirmativo del deseo. Esta positividad solo la encontramos en el Inconsciente desmemoriado en el que todo vive y no puede, por tanto, ser disfrutado, bajo la forma de un estado anímico del yo consciente, nacido de la sujeción al lenguaje, tal y como lo relata el discurso lacaniano.

Lyotard recoge de Freud otro concepto, el de figura, que se sitúa entre el proceso primario y el secundario, participando de alguna manera de ambos. Llama figura a un dispositivo libidinal que distribuye la energía en cometidos y funciones, haciéndola circular por determinados ámbitos. Usaremos el término figura para hablar del fantasma, y así Lyotard dice: "Toda fanstasmática procede de un desposeimiento, pero también toda fantasmática consiste en cercar el vértigo que suscita en una figuración inaugural y constante, este espacio de ausencia como su lugar contenido" ${ }^{20}$. Es decir, hay algo en el fantasma de deseo-libido, por cuanto invita a la disolución del sujeto yóico en una "mascarada" sin fondo; pero asimismo, esta mascarada se constituye en una teatralidad que consiste en operaciones de representación posibilitadas por un dispositivo lingüístico y mediatizadas por la conciencia. El fantasma, como sabemos, se forma en la prohibición del deseo, prohibición que el deseo introyecta, prohibición que obliga al deseo a circular por un camino regresivo, único, que le permite un cumplimiento o un pseudocumplimiento. El

\footnotetext{
${ }^{18}$ Cfr. Ver "La pintura como dispositivo libidinal" en J. F. Lyotard: Dispositivos pulsionales. op.cit. pp.225-227; también "Notas sobre la función crítica de la obra" en A partir de Marx y Freud. op.cit. p.234. El deseo-voto es también llamado deseo-propósito y tematizado en "Sobre una figura de discurso" en Dispositivos pulsionales, pp.126-127.

${ }^{19}$ Cfr. Un ejemplo de ello lo encontramos en I. Kant: Crítica de la razón práctica (citado en F. A. Velasco: La moral kantiana. Ed. Andrés Bello. Santiago de Chile, 1992. p. 74), cuando habla de cómo la voluntad entra a formar parte de la razón pura, produciendo conocimiento práctico de lo suprasensible en el campo de la libertad: "la facultad de desear es la facultad (de un ser vivo) de ser, por medio de sus representaciones, causa de la realidad de los objetos de esas representaciones".

${ }^{20}$ J. F. Lyotard: A partir de Marx y Freud. op.cit. p. 72.
} 
fantasma no deja de ser una puesta en escena, una escena otra que no es la de la "realidad", una escena que puede burlar las exigencias de absorción de la energía psíquica en el sistema lingüístico y de la lógica de la percepción, pero una escena maquinada desde la prohibición, desde la retirada del significante que direcciona el deseo-voto ${ }^{21}$.

Para tematizar el deseo, Lyotard echa mano de otro concepto freudiano, el de pulsión de muerte. Lyotard elimina las equívocas connotaciones que este término toma en El malestar en la cultura, haciéndose eco, para ello, del combate que Deleuze y Guattari tienden a la hipótesis freudiana de la agresividad introyectada y de la mala conciencia. Así, estamos en disposición de ligar la pulsión de muerte al Deseo o deseo-libido. La pulsión de muerte, lejos de relacionarse con ninguna especie de sadismo, es, simplemente, la idea de que la máquina de propagar energía y de ligarla no está perfectamente regulada en una mecánica. Con esto se quiere decir que las máquinas solo funcionan descompuestas y lejos de una armonía o sistema. La pulsión de muerte tiene relación con el Inconsciente, con la Substancia spinozista, con el cuerpo sin órganos, con el "lenguaje del Ser": desconoce los esquemas de causa-efecto, la temporalización crónica, la negación, la disyunción excluyente... y solo opera mediante desplazamientos (recordando el funcionamiento del sueño). Es un deseo que opera en las intensidades extremas, las intensidades libidinales no reguladas por el lenguaje ni la Ley. Éste sería el tratamiento particular que Lyotard hace del Inconsciente como Diferencia, resumido en la positividad de la pulsión de muerte, ignorancia de las separaciones reguladas, de los vacíos, de las fronteras, y de las jerarquías. Es la positividad en la que todo se da "a la vez"; es la positividad del Inconsciente, del olvido en sentido nietzscheano, que hace que todo sea contemporáneo y vivo. Respecto a esta pulsión de muerte, la figura es un operador de transformación que estabiliza en algunos puntos la energía haciéndola reposar bajo la apariencia de objetos. La pulsión de muerte es un no-principio de exceso, de desbordamiento, de un goce que no solo sirve a la propagación (reproducción) sino a la perversión (esterilidad). Lyotard parece referirse al goce de la creación-destrucción propia del niño nietzscheano que despilfarra energía: "Es un goce que yendo más allá del punto de regreso derrama las fuerzas libidinales fuera del conjunto"22. Estamos en un desrégimen, en las antípodas del proceso secundario ${ }^{23}$. La pulsión de muerte tal y como la trata Lyotard, se asemeja a la recepción que hace Bataille, en cuyos escritos se relaciona la muerte con la vivencia ontológica de la continuidad entendida ésta como ápeiron.

Lyotard observa que casi todo sirve para disipar el deseo, o lo que es lo mismo, para desviarlo hacia las palabras y hacia todo lo que tiene un efecto ansiolítico. Así, podemos referirnos a los dispositivos. Lyotard Ilama la atención especialmente sobre el dispositivo del lenguaje, que permite la absorción de la libido en el lenguaje, que actuaría como canal, como debilitador de las pasiones. Así, llegaríamos a la temática del discurso como dispositivo que capta la intensidad y la refiere a los términos presentes de algún diálogo. Del dispositivo discursivo nace la responsabilidad y de ésta el sujeto, ese vacío del que habla Lacan, y que da cuenta, sin embargo, de una infinidad de enunciados potenciales. Es dentro de este dispositivo, donde Lyotard sitúa la institución psicoanalítica, también como dispositivo. Para establecer la teoría del psicoanálisis como dispositivo pulsional, Lyotard nos ofrece algunas características, de entre las cuales, destaca el privilegio que el psicoanálisis otorga al lenguaje, como campo en el que es posible representar el deseo (y por tanto suavizarlo, doblegarlo). El psicoanálisis toma el habla como objeto y el diálogo

\footnotetext{
${ }^{21}$ Cfr. Ver J. F. Lyotard:. A partir de Marx y Freud. op.cit. pp. 35, 59-62 y 235.

22 J. F. Lyotard: Dispositivos pulsionales. op.cit. p.53.

${ }^{23}$ Cfr. Seguir el asunto de la pulsión de muerte en las siguientes partes de Dispositivos pulsionales. op.cit.: "Sobre una figura de discurso", "Capitalismo energúmeno", p.47 y "Varios silencios", pp. 266-267.
} 
como cura, como trabajo que hace pasar de lo menos a lo más ligado, de la imagen a la palabra, del devenir a la definición, de lo incomunicable a lo comunicable ${ }^{24}$. Lyotard habla de la representación como conversión de intensidades en intenciones. Esta conversión está siempre mediada por el lenguaje: "Toda elevada emoción es efecto de muerte, disolución de lo acabado, de lo histórico. La voluntad de poder como pulsión afirmativa de lo singular hace que el Eterno Retorno no sea el de lo Mismo, es decir, de un algo que se re-presentaría en las singularidades, convertidas a partir de entonces en <<intenciones>>. En el centro del Retorno, no hay nada. No hay centro. Las singularidades remiten unas a otras, sin referencia al centro, al Sujeto, al Significante, etc." ${ }^{25}$. El psicoanalista quisiera decir lo que desea la gente pero el deseo no es capturable en ningún discurso, ni de saber ni de poder. El que pretende representar al deseo, sabiéndolo y diciéndolo sería el educador, el moralista, el cura... ${ }^{26}$.

Finalmente, Lyotard se decide a denominar "acontecimiento" al impacto de flujos de energía, en cantidad tal, sobre el sistema, que éste no alcanza a sujetarlo y canalizarlo, de tal modo que el encuentro de esta energía libidinal con la institución orgánica sería traumático. La fuerza cuantitativa del acontecimiento va pareja al misterio del desplazamiento constante del deseo ${ }^{27}$. Así, entendemos, a partir de ahora, lo que se quiere mentar en la apuesta por una política del Acontecimiento. Se trataría de buscar las condiciones de posibilidad para un desbordamiento de los flujos de deseo por fuera de las capturas y dispositivos preparados por el sistema. Una política del Acontecimiento implica, por tanto, la necesidad de una torsión de los lenguajes y de los discursos.

Lyotard encuentra que las mismas operaciones que Freud describe como propias del sueño o del síntoma, son las que usa el orden del preconsciente en el proceso secundario, en la absorción de energía por el lenguaje. Tienen como finalidad disfrazar el deseo por ser éste intolerable, inquietante, raro, informe, abismático, el más acá de la buena forma, de lo armonioso, complaciente y familiar; por ser, en definitiva, del campo del Inconsciente. Lyotard entiende también que existe en el psicoanálisis al menos un pretendido ejemplo de comunicación de inconscientes en esa doble norma que obliga al analizado a disolverse en el ejercicio de la libre asociación y al analista a prestar una atención flotante. En esta doble tarea se nos invita, por de pronto, a abrir un área fantasmática pero libre de estructuraciones del proceso secundario. Nos encontraríamos ante el deseo de decir el deseo y su consiguiente trágica imposibilidad ${ }^{28}$.

También queremos abordar la temática de la positividad del Inconsciente, de ese "lenguaje del Ser" que no entiende de negaciones y en el cual vive el "a la vez" del pensamiento sin mala conciencia que olvida y todo conserva. Sin embargo, nada nos parece más expresivo que presentar para este asunto las propias palabras de Lyotard: "Bachelard dice que la imaginación no conoce al no ser (...), que con el ensueño está uno bañado en un medio sin obstáculos en el que ningún ser dice no (...). Freud: no hay en este sistema ni negación, ni duda, ni grado en la certeza. Entendamos que por esa

\footnotetext{
${ }^{24}$ Cfr. Para esta cuestión ver G. Vattimo: El sujeto y la máscara. de. Península. Barcelona, 2003, sobre todo el cap. III de la Primera parte: "Redefinición de la decadencia. Muerte de la tragedia y triunfo de la ratio", donde Vattimo presenta citas del propio Nietzsche en La gaya ciencia, en las que se pregunta para qué sirve una conciencia si en esencia es superflua. Podemos ver que la fuerza de la conciencia se encontraría siempre en relación con la capacidad de comunicación y que la capacidad de comunicación se encuentra en relación con la necesidad de comunicación. J. F. Lyotard: Dispositivos pulsionales. op.cit. p. 288 y A partir de Marx y Freud, p. 230, donde opone el Inconsciente al lenguaje.

25 J. F. Lyotard: Dispositivos pulsionales. op.cit. p. 299.

${ }^{26}$ J. F. Lyotard: A partir de Marx y Freud. op.cit. p. 19.

27 Ibid. pp. 306-308.

${ }^{28}$ Cfr. Lyotard trata el arte como deseo de ver el deseo. Ver "Principales tendencias actuales del estudio psicoanalítico de las expresiones artísticas y literarias" en A partir de Marx y Freud. op.cit. p. 77.
} 
ausencia de la negación, es la articulación, en tanto que basada sobre la separación y la oposición, lo que resulta imposible, y excluidas con ella todas las formas del discurso. El No que falta al inconsciente feliz es únicamente (...) el No del padre, que es también su nombre. La ausencia del padre es la señal del placer, del desarreglo, todo es acogido (...); ese Sí está fuera del sistema, fuera de la máquina de fantasmas (...); es el principio de todo desplazamiento (...) Las formas se acaban, las materias nunca" ${ }^{29}$.

Trataremos ahora de observar algunas de las apreciaciones de Lyotard sobre el Inconsciente que nos llevan a entenderlo como lo opuesto a la representación, como zona libre de operaciones representativas, como zona a la que únicamente podríamos acceder mediante una máquina deconstructiva. Así, entendemos que el trabajo filosófico de deconstrucción es el auténtico "trabajo de verdad", y nosotros diremos también, el verdadero descubridor de las infraestructuras, porque el desorden, la desorganización molecular es la única base y ésta no equivale sino el deseo-libido fluyendo y desbordándose, dispensándose ${ }^{30}$. La deconstrucción sacude los fundamentos de la significación para encontrar aquello que la conciencia adaptativa rechaza para constituirse. Este trabajo lo advierte Lyotard en Freud, en un Freud liberado del gusto por la elaboración de tópicos.

El espacio inconsciente se presenta, para Lyotard, con las características del Acontecimiento, que desmonta los preceptos de la lógica, de la ética, de la justificación... Ya sabemos lo que el psicoanálisis supone, en cuanto dispositivo discursivo: en el diván, la función asignada a la representación es el reconocimiento del desconocimiento por parte del analizado. Según Lyotard, "Freud comienza a percibir lo que es la otra escena, el inconsciente, y a señalar la neurosis como imposibilidad de representación" ${ }^{31}$. La posición de Lyotard frente al psicoanálisis sigue siendo oscilante y es que Lyotard reclama el "fin de la representación, si representar es presentar en ausencia suya algo -pero aun/además representación si representar es presentar a pesar de todo, presentar lo impresentable, representar en el sentido de amonestar a alguien, darle una reprimenda. Porque lo que se reprime es el desorden..." ${ }^{32}$. Y más adelante observa que tal vez lo importante en el dispositivo representativo no sea lo regulado ni lo perdido sino la distorsión y la diferencia. De nuevo vuelve a aparecer el paralelismo entre el trabajo psicoanalítico y el trabajo artístico. Si en algo el psicoanálisis sigue preso del clásico dispositivo representativo reactivo, es en su consideración de la imagen (y por tanto del fantasma, de la escena onírica, etc.) como significación pálida, como pantalla que hay que atravesar, o lo que es lo mismo, como cosa a la que hay que hacer hablar, arrancarle las palabras. Freud seguirá anclado en la moderna obsesión por desenmascarar ${ }^{33}$.

Lyotard también criticaría, como lo harán Deleuze y Guattari, una concepción del Inconsciente como teatro, ya que el nihilismo es inherente a la representación teatral, que trata de sustituir el mero desplazamiento por direcciones fijas propias del sentido. Esto responde ya a una clara infiltración de la conciencia, que inyecta sus patrones en el Inconsciente. Aún encontramos en Freud una teología laica en su funcionamiento como dispositivo de representación terapéutico.

Lyotard combate la afirmación lacaniana que dice que el Inconsciente está estructurado como un lenguaje, enfrentándole al propio Freud de La interpretación de los sueños, que distingue claramente entre el proceso primario y el secundario como no lingüístico y lingüístico, respectivamente. El Inconsciente no es lingüístico y la operación

\footnotetext{
29 J. F. Lyotard: Dispositivos pulsionales. op.cit. pp. 165-166.

${ }^{30}$ Cfr. Ésta es la tesis que se recorrerá en J. F. Lyotard: Economía libidinal.

31 J. F. Lyotard: A partir de Marx y Freud. op.cit. p. 186.

32 J. F. Lyotard: Dispositivos pulsionales. op.cit. p. 9.

${ }^{33}$ Cfr. Seguir este asunto en "Freud según Cézanne" en Dispositivos pulsionales. op.cit. p. 70.
} 
deconstructiva freudiana así lo revela. El Inconsciente como máquina de producción libre de "realismos" perceptivos y de discursos significativos se manifiesta de modo privilegiado en el anti-arte, por ejemplo en el pop-art ${ }^{34}$.

Finalmente decimos que bajo la escritura de Lyotard, el Inconsciente sería un espacio que nunca podrá ser contactado por un sujeto, ya que lo que escapa a la representación escapa, en consecuencia, al sujeto, que no es sino un producto de aquélla. Lyotard apuesta, como Nietzsche, por un más allá del hombre, por Dionisos, como figura de las intensidades fluidas, cuya audacia consiste en abandonar la tarea del dominio del cuerpo para disolverse, en cambio, en su funcionamiento ${ }^{35}$.

\section{Bibliografía:}

J. ALEMÁN y S. LARRIERA: Lacan: Heidegger. El psicoanálisis en la tarea del pensar. Málaga, Miguel Gómez,1998.

G. BATAILLE: Las lágrimas de Eros. Barcelona, Tusquets, 2007.

El erotismo. Barcelona, Tusquets, 2007.

G. DELEUZE: Logique du sens. Paris, Les Éditions de Minuit, 1969 (Lógica del sentido. Ed. Paidós, Barcelona, 1989).

con F. GUATTARI: Capitalisme et schizophrénie tome 1: I'Anti-Oedipe, Paris: Éditions de Minuit, 1972 (Trad. Cast. El Antiedipo, Barcelona: Barral, 1973, por Francisco Monge. Reditado por Paidós, Barcelona 1998).

J. DERRIDA: La escritura y la diferencia. Barcelona, Anthropos, 1989.

La tarjeta postal. De Sócrates a Freud y más allá. México D. F., Siglo XXI, 2001.

Márgenes de la filosofía. Madrid, Cátedra, 2006.

M. FOUCAULT: Les Mots et les Choses. Une archéologie des sciences humaines. Paris, Gallimard, 1966. Trad. Cast. Las palabras y las cosas: una arqueología de las ciencias humanas. México, Siglo XXI, 1968, 1999.

El pensamiento del afuera, Valencia, Pre-textos, 1989.

Historia de la sexualidad 1. La voluntad de saber. México, Siglo XXI, 2006.

Historia de la sexualidad 2: El uso de los placeres. México, Siglo XXI, 2006.

Historia de la sexualidad 3: El cuidado de sí. México, Siglo XXI, 2005.

S. FREUD: Obras completas. Barcelona, RBA, 2006.

F. GUATTARI: L'inconscient machinique: essais de schizo-analyse. Paris, Recherches, 1979.

\footnotetext{
${ }^{34}$ Cfr. Ver "Notas sobre la función crítica de la obra" en A partir de Marx y Freud. op.cit. p. 244.

35 J. F. Lyotard: Dispositivos pulsionales. op.cit. p. 301.
} 
M. HEIDEGGER: Conferencias y artículos. Barcelona, Ed. del Serval, 2001. De camino al habla. Barcelona, Ed. del Serval, 2002.

De la esencia de la verdad. Barcelona, Herder, 2007. Hitos. Madrid, Alianza, 2000.

J. LACAN: Escritos 1. México, Siglo XXI, 2001.

Escritos 2. México, Siglo XXI, 2001.

Seminario 3, Las Psicosis. Buenos Aires, Paidós, 2010.

Seminario 8: La transferencia. Buenos Aires, Paidós, 2003.

Seminario 14:Lógica del fantasma. Clase 20. Del 31 de Mayo de 1967. http://www.tuanalista.com/Jacques-Lacan/14956/Seminario-14-La-logica-del-fantasmapag.1.htm

Seminario 20: Aún. Buenos Aires, Paidós, 1989.

J.-F. LYOTARD: La condición postmoderna. Madrid, Cátedra, 1994.

A partir de Freud y Marx. Madrid, Fundamentos, 1975.

Dispositivos pulsionales. Madrid, Fundamentos, 1981.

La condición postmoderna (libre en la red).

Lectures d'enfance. Paris, Galilée, 1991.

G. VATTIMO: El sujeto y la máscara. Nietzsche y el problema de la liberación. Barcelona, Península, 2003. 